\title{
Efficacy of Avosoya®300 (Avocado/Soybean Unsaponifiables) on Cartilage Catabolic Biomarkers among Egyptian Patients with Early Symptomatic Knee Osteoarthritis
}

\author{
Hesham Hamoud ${ }^{1 *}$, Gamal Hosny ${ }^{2}$, Mohamed A Hanafy ${ }^{3}$ and Mahmoud I Risha ${ }^{4}$ \\ ${ }^{1,3,4}$ Department of Rheumatology and Rehabilitation, Al-Azhar University, Egypt \\ ${ }^{2}$ Department of Orthopedic surgery, Benha University, Egypt
}

Submission: February 17, 2020; Published: March 05, 2020

*Corresponding author: Hesham hamoud, Department of Rheumatology and Rehabilitation, Al-Azhar University, Egypt

Abstract

Background: Biochemical catabolic biomarkers receive increasing attention in early stage of osteoarthritis (OA), due to superior sensitivity and objectivity in comparison to conventional endpoints. While previous studies with biochemical biomarkers in OA have focused primarily on structural changes, this study focused on early OA stage associated knee pain. Early determination would allow progressing personalized treatment choices and leading to better management of patients with $\mathrm{OA}$.

Objective: To estimate and compare urinary levels of C-telopeptides of type II collagen (CTX-II) and serum levels of Cartilage Oligomeric Matrix Protein (COMP) for assessing efficacy of Avocado/Soybean Unsaponifiables (ASU) in patients having early symptomatic knee osteoarthritis (ESKOA).

Patients and Methods: In this multicentric prospective observational study we recruited 280 patients with early stage knee osteoarthritis according to Migliore, et al. [1] criteria for definition of early symptomatic knee osteoarthritis (ESKOA)1. All cases received ASU (300 mg capsules twice/day orally) and were assessed by pain on visual analogue scale (100 mm VAS), urinary CTX-II (uCTX-II) and serum COMP (sCOMP) at the baseline and after six months.

Results: There was a highly significant decline in the median urinary CTX-II levels after 6 months therapy $(19.8 \mathrm{ng} / \mathrm{ml})$ compared to the base line level $(198.5 \mathrm{ng} / \mathrm{ml})$ where P value ( 0.001$)$,however there was a non-significant decrease in the median serum COMP level after 6 months therapy $(2252.2 \mathrm{pg} / \mathrm{ml})$ compared to the base line level $(1995.4 \mathrm{pg} / \mathrm{ml})$. The median pain VAS score showed a highly significant improvement after 6 months therapy declined to (15.75 - $28.75 \mathrm{~mm})$ VAS compared to VAS score at the base line was (( $30-47.5 \mathrm{~mm})$ VAS .

Conclusion: These results suggest that ASU supplement might improve the pain and quality of life through regression of known inflammatory cartilage biomarkers in early symptomatic knee OA patients. Future randomized double-blind Controlled study is needed to confirm our findings.

Keywords: Early symptomatic knee Osteoarthritis; Urinary CTX-II; Serum COMP; Avocado/soybean unsaponifiables.

\section{Introduction}

Osteoarthritis $(\mathrm{OA})$ is a low-grade inflammatory disease of synovial joints and by far the most common form of arthritis [2]. Causing chronic pain and physical, psychic and social disability in older individuals [3], it is characterized by progressive deterioration and loss of hyaline cartilage [4] with concomitant structural and functional changes in the whole joint components, whatever the synovium, meniscus, periarticular soft tissues, and subchondral bone [5]. The major risk factors for OA development include age, obesity and metabolic disease $[6,7]$. Although OA has been viewed as a "degenerative" disease for many decades, it is generally nowadays accepted to be an inflammatory and biomechanical whole-organ disease [9]. The pathogenesis and progression of $\mathrm{OA}$ is influenced by several factors including bone shape and joint dysplasia [10], obesity [11], synovitis [12], complement proteins [13], inflammatory mediators [14], inflammaging [15,16], innate immunity [17], 
low-grade inflammation [18] induced by metabolic syndrome [19] and diabetes mellitus [20].

Avocado/soybean Unsaponifiable (ASU) are natural vegetable extracts made from avocado and soybean oils, consisting of the leftover fraction (approximately 1\%) that cannot be made into soap after saponification. ASU is composed of one third avocado and two thirds soybean, the major components of ASU are phytosterols $\beta$-sitosterol, camp sterol, and stigmasterol, which are rapidly incorporated into cells. ASU is a complex mixture of many compounds including fat-soluble vitamins, sterols, triterpene alcohols, and possibly furan fatty acids.

The identity of the active component remains unknown. The sterol contents of Avocado/soybean preparations are the primary contributors to biological activity in articular chondrocytes [21]. Avocado/soybean Unsaponifiable possesses chondroprotective, anabolic, and anticatabolic properties. It inhibits the breakdown of cartilage and promotes cartilage repair by inhibiting a number of molecules and pathways implicated in $\mathrm{OA}$, also stimulates the synthesis of collagen and aggrecan by inhibiting inflammatory cytokines such as IL-1, IL-6, IL8, TNF, and PGE2 through modulation of NF-kappa B [22]. Crosslinked C-telopeptides of type II collagen (CTX-II) and Cartilage oligomeric matrix protein (COMP) are two biochemical markers; they are degradation products of joint tissues, especially the cartilage extracellular matrix, and can potentially predict the destruction of articular cartilage in $\mathrm{OA}$.However, many studies of early OA diagnosis have only measured one of these two biomarkers at a single time point during the pathological process of OA [22].

Cartilage homeostasis relies on the controlled catabolism of matrix proteins such as collagen and the replacement with newly synthesized proteins by chondrocytes [19]. Type II collagen, the major protein and collagen type in articular cartilage, is synthesized as a procollagen with a propeptide domain [20]. The increased urinary carboxy-terminal telopeptide of type II collagen (uCTX-II), a degradation product of type II cartilage, predict progression of radiographic knee OA in several studies [23], sCOMP concentrations were found to be significantly higher in knee osteoarthritis with early signs of cartilage damage. The serum level of cartilage oligomeric matrix protein sCOMP levels were the highest significantly associated with the development of radiographic OA changes and painful radiographic knee OA [24].uCTX-II and sCOMP were significantly \& consistently associated with $\mathrm{OA}$ incidence (defined as $\mathrm{KL}<2$ at baseline and KL 2 at follow-up) and progression (defined as $\uparrow$ KL1 between baseline \& follow-up) [25].

\section{Objective}

To evaluate the efficacy of Avosoya in treatment of early symptomatic knee osteoarthritis (ESKOA) through: -

i. $\quad$ Changes in the disease symptoms (pain) in the early stage using visual analogue scale (VAS) pain. ii. Changes in serum levels of Cartilage oligomeric matrix protein (sCOMP) \& the urinary crosslinked C-telopeptide of type II collagen (uCTX-II) that indicate hyper catabolic status of the cartilage in ESKOA.

\section{Patients and Methods}

\section{Study Design, Setting and Duration}

This multicentric prospective observational study was carried out among ten different Egyptian governorates from Feb 2019 till Jul 2019. All participants signed informed consent prior to inclusion according to the Declaration of Helsinki (as amended by the 59th General Assembly, Seoul, 2008). Where 280 patients with ESKOA were recruited, blood and urine samples were collected at baseline and 6 months later, specific data regarding patient recruitment, allocation and follow-up are presented in Figure 1. The concentration of the two different biomarkers will be determined at each time point and the data will be analyzed by statistical methodology.

\section{Interventions}

All Cases received ASU (Avosoya $300 \mathrm{mg}$ capsules once/ day orally) for six months according to standard management algorithm on the guidelines of Osteoarthritis Research Society International (OARSI)[8].

\section{Inclusion Criteria}

Female and male patients between 30 and 45 years old with at least 2 mandatory symptoms according to Migliore et al. [1]

a. Any Knee pain in the absence of any recent trauma or injury and

b. Very short joint stiffness, lasting 5-10 min, when starting movement

c. Lasting $<6$ months.

\section{Exclusion Criteria}

i. Active inflammatory arthritis or generalized pain.

ii. $\geq 50$ years

iii. $\geq 40$ years if at least 1 risk factor present

iv. Kellgren and Lawrence $>0$

v. Any recent trauma or injury.

\section{Outcome Measures}

\section{The primary endpoints}

a. To compare the change from baseline to 6 months in sCOMP \& uCTXII

b. To compare the change from baseline to 6 months in Knee Pain VAS. patients were asked to memorize and report the maximal knee pain experienced within the last 24 hours on a $100 \mathrm{~mm}$ VAS. 


\section{The secondary endpoints were to characterize changes in}

i. Activities of daily living (ADL), the quality of life,

ii. Frequency of knee pain after 6 months iii. Severity of knee pain after 6 months

iv. Limitation of Activities from the knee pain after 6 months

v. Incidence of analgesic use for knee pain after 6 months (Figure 1).

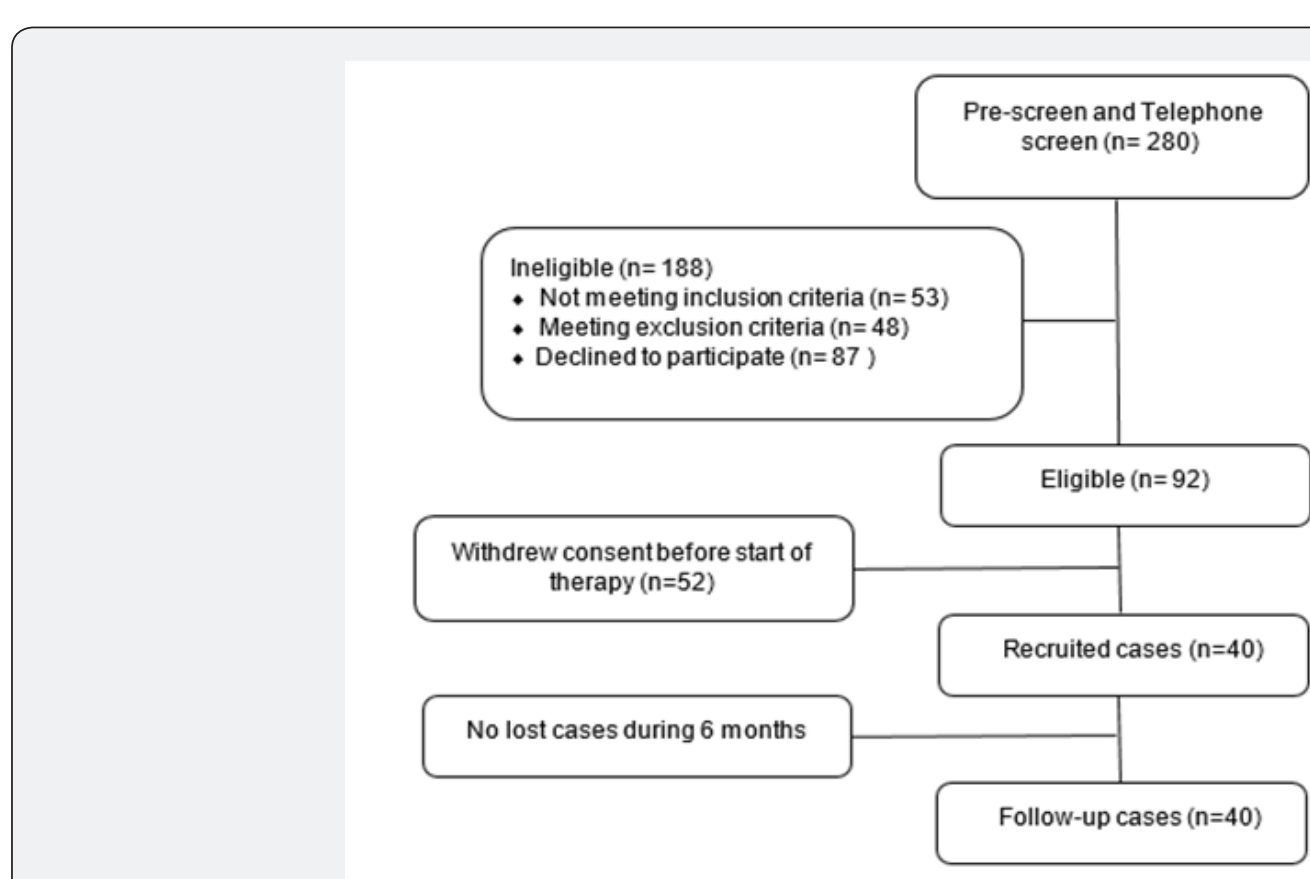

Figure 1: Algorism of recruitment and follow-up of study participants.

All patients were made to rest for half an hour in seated position. Blood samples were drawn in late mid-day to avoid diurnal variations. Five $\mathrm{ml}$ whole venous blood sample were drawn in syringe and collected in plain vial with aseptic technique. Also, all subjects' urine samples were taken in early morning on the same day. Samples were sent to laboratory for estimation of serum COMP levels and urinary CTX-II levels by ELISA test.

\section{Follow up}

At the end of follow up, all cases were taken the blood and urine samples. Improvement in pain and functionality was recorded on VAS scale.

\section{Statistical Analysis}

The recorded data were statistically analyzed using the statistical software package SPSS version 26. Normality of variables was assessed using Shapiro-Wilk normality test. Nonparametric data were summarized as Median \pm Interquartile range. Comparison between repeated measurements on a single sample was done by Wilcoxon signed-rank test. Spearman's correlation test was performed to study linear/nonlinear correlation between variables. The significance level was set at p-value $<0.05$.

\section{Results}

A total of $40 \mathrm{OA}$ patients (32 females, 8 males) aged 37 years $(35.2 \pm 4.2)$ were enrolled, to participate in our study. Characteristics of the study population are presented in Table 1. There was a highly significant decline in the median urinary CTXII levels after 6 months therapy $(19.8 \mathrm{ng} / \mathrm{ml})$ compared to the base line level $(198.5 \mathrm{ng} / \mathrm{ml})$ where P value ( 0.001 ) ,however there was a non-significant decrease in the median serum COMP level after 6 months therapy $(2252.2 \mathrm{pg} / \mathrm{ml})$ compared to the base line level (1995.4 pg/ml).

Table 1: Demographic data and baseline characteristics of all patients $(n=40)$.

\begin{tabular}{|c|c|}
\hline Variables & $\mathbf{n = 4 0}$ \\
\hline Age (years) & $35.2 \pm 4.2$ \\
\hline Gender (female /male) & $32 / 8$ \\
\hline BMI $\left(\mathrm{kg} / \mathrm{m}^{2}\right.$ ) & $25.2 \pm 2.4$ \\
\hline Affected Knee (left/right) & $8 / 32$ \\
\hline Years with knee pain & $0.7 \pm 0.1$ \\
\hline Kellgren-Lawrence grading: & G 0 35 patients / G 1 5 patients \\
\hline 24-hour VAS (mm) & $42.3 \pm 22.8$ \\
\hline
\end{tabular}

The median pain VAS score showed a highly significant improvement after 6 months therapy declined to ((15.75 - 28.75 
$\mathrm{mm}$ ) VAS compared to VAS score at the base line was ( $(30-47.5$ $\mathrm{mm}$ ) VAS (Table 2 \& Figure 2). Pair wise correlation analysis of each of the two biochemical biomarkers and VAS score parameter. There was a significant positive correlation observed between difference of CTX-II and VAS score $(\mathrm{r}=0.40, \mathrm{p}<0.05)$ (Table 3 \& Figure 3), however there was a statistically significant correlation $((\mathrm{r}=0.08, \mathrm{p}>0.05))$ between differences of Serum COMP and VAS score (Table 4 \& Figure 4 ).

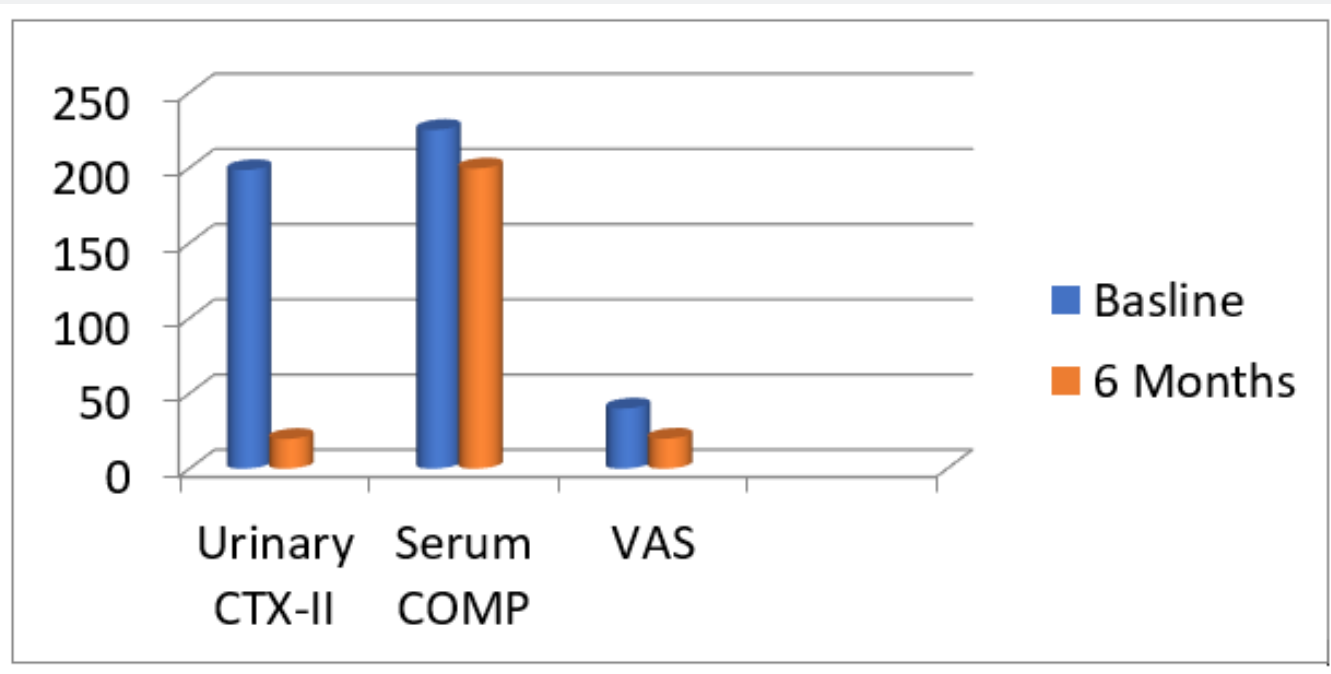

Figure 2: Comparisons between Urinary CTX-II, Serum COMP and VAS score at the base line and after 6 months treatment.

Table 2: Comparisons between Urinary CTX-II, Serum COMP and VAS score at the base line and after 6 months treatment.

\begin{tabular}{|c|c|c|c|c|c|c|}
\hline & No. & $\begin{array}{c}\text { Pre-treatment } \\
\text { Median (IQR) }\end{array}$ & $\begin{array}{c}\text { Post-treatment } \\
\text { Median (IQR) }\end{array}$ & $\begin{array}{c}\text { Difference } \\
\text { Median (IQR) }\end{array}$ & z-score & p-value \\
\hline $\begin{array}{c}\text { Urinary CTX-II } \\
(\mathrm{ng} / \mathrm{ml})\end{array}$ & 40 & $\begin{array}{c}198.5 \\
(135.9-223.1)\end{array}$ & $\begin{array}{c}19.8 \\
(11.2-24.2)\end{array}$ & $\begin{array}{c}-179.0 \\
(-203.9--127.9)\end{array}$ & -5.5 & $\mathbf{0 . 0 0 1}$ \\
\hline $\begin{array}{c}\text { Serum COMP } \\
(\mathrm{pg} / \mathrm{ml})\end{array}$ & 40 & $\begin{array}{c}2252.2 \\
(1564.9-2658)\end{array}$ & $\begin{array}{c}1995.4 \\
(1750.7-2278.9)\end{array}$ & $\begin{array}{c}128.6 \\
(-738.3-719.6)\end{array}$ & -0.2 & $\mathbf{0 . 7 7 8}$ \\
\hline $\begin{array}{c}\text { VAS } \\
(\mathrm{mm})\end{array}$ & 40 & $\begin{array}{c}20 \\
(30-47.5)\end{array}$ & $\begin{array}{c}20 \\
(15.75-28.75)\end{array}$ & -5.0 & $\mathbf{0 . 0 0 1}$ \\
\hline
\end{tabular}

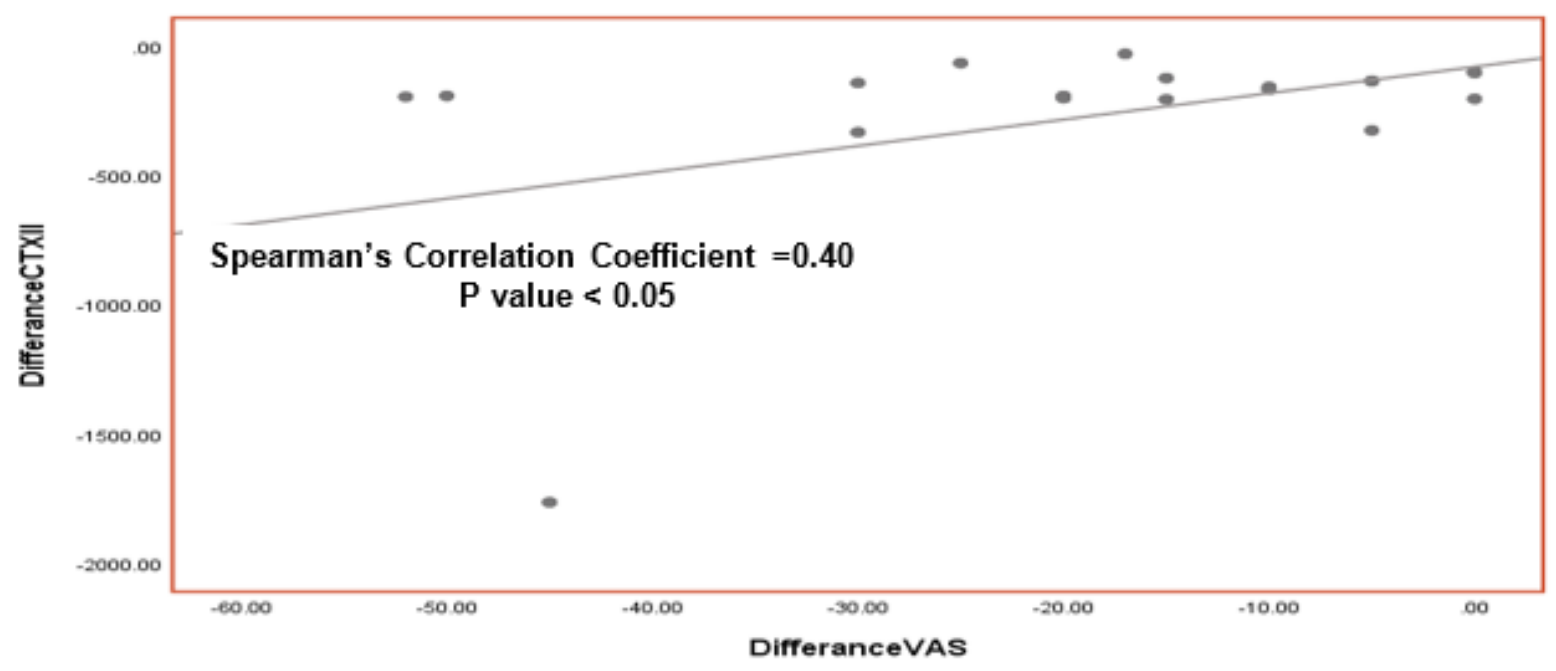

Figure 3: Coefficients and related $p$-values. 


\section{Orthopedics and Rheumatology Open Access Journal (OROAJ)}

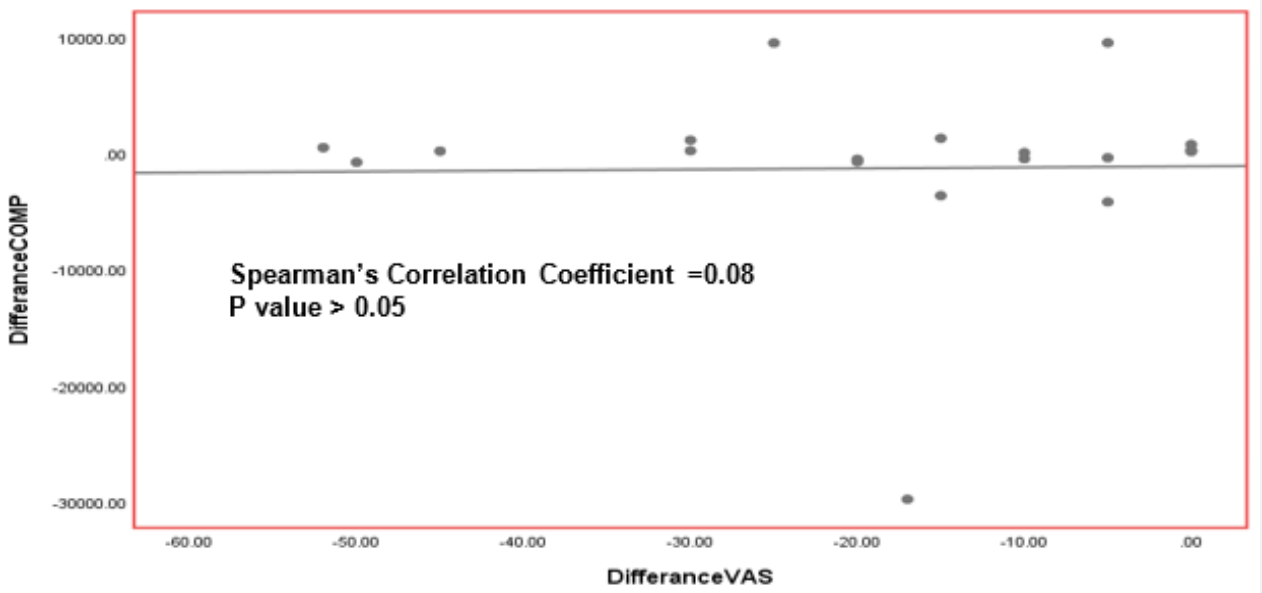

Figure 4: Scatter plots of Difference VAS vs. Difference serum COMP. Spearman correlation coefficients and related p-values are given.

Table 3: Correlation between differences on Urinary CTX-II and VAS score.

\begin{tabular}{|c|c|c|c|}
\hline \multicolumn{2}{|c|}{ Correlation } & \multicolumn{2}{c|}{ (Difference of VAS score) } \\
\hline \multirow{3}{*}{$\begin{array}{l}\text { Spearman's } \\
\text { Correlation }\end{array}$} & \multirow{2}{*}{ (Difference of Urinary CTX-II) } & Correlation Coefficient (r) & 0.40 \\
\cline { 3 - 4 } & & Sig. (2-tailed) & 0.02 \\
\cline { 2 - 4 } & & Number & 40 \\
\hline
\end{tabular}

Table 4: Correlation between differences on Serum COMP and VAS score.

\begin{tabular}{|l|c|c|c|}
\hline \multirow{2}{*}{ Spearman's Correlation } & \multirow{2}{|c|}{ Correlation } & \multicolumn{2}{c|}{ (Post-Pre-treatment of VAS score) } \\
\hline \multirow{2}{*}{$\begin{array}{c}\text { (Post-Pre-treatment } \\
\text { of serum COMP) }\end{array}$} & Correlation Coefficient ( $\mathrm{r}$ ) & 0.08 \\
\cline { 3 - 4 } & & Sig. (2-tailed) & 0.60 \\
\cline { 3 - 4 } & & Number & 40 \\
\hline
\end{tabular}

\section{Discussion}

Usually, knee OA diagnosis is based on the radiological irreversible changes and by pain assessment caused by joint tissue destruction. Therefore, attention must be focused on developing assays for biochemical markers which are released from cartilage and its degradation in the very early stages [26]. Biomarkers have the capacity to detect early joint degradation in such diseases. They can provide useful diagnostic and prognostic information by reflecting disease relevant biological activity in the joint and predict the course of disease progression. Also, they can serve as an alternative tool for the discovery of the response to the disease modifying osteoarthritis drugs (DMOADs) [27]. Our study showed a significantly difference improvements in Urinary CTX-II and VAS score in early symptomatic knee osteoarthritis (ESKOA) patients after receiving Avocado/ soybean Unsaponifiable (ASU) treatment for six months in a single am clinical study.

The results of the present study showed a highly significant decline in the median urinary CTX-II levels after 6 months therapy $(19.8 \mathrm{ng} / \mathrm{ml}$ ) compared to the base line level (198.5 $\mathrm{ng} / \mathrm{ml}$ ) where $\mathrm{P}$ value ( 0.001 ), however there was a nonsignificant decrease in the median serum COMP level after 6 months therapy (2252.2 $\mathrm{pg} / \mathrm{ml}$ ) compared to the base line level (1995.4pg/ml),consistent with that noted by other investigators, uCTX-II and sCOMP were significantly associated with the incidence (defined as $\mathrm{KL}<2$ at baseline and KL 2 at follow-up) and progression (defined as KL 1 increase between baseline and follow-up) of OA [28].

There have been a limited number of studies during the past years that attempted to validate existing OA biomarkers in the context of a clinical DMOAD trial. Karsdal et al. [29] studied uCTX-I, uCTX-II and serum osteocalcin in the context of two large phase III knee OA trials of oral salmon calcitonin. In contrast to our result, the Chingford cohort study, which has 20 years of data on development of radiographic knee OA progression in a cohort of middle-aged women with Kellgren and Lawrence (KL) scores of zero at baseline, sCOMP levels in the highest quartile were significantly associated with the development of radiographic knee $\mathrm{OA}$ and painful radiographic knee $\mathrm{OA}[30]$, and this may be explained by the very long follow up period the Chingford cohort study which needed to explore the sCOMP level changes. Van Spil WE et al stated that the, uCTX-II and sCOMP were the most consistently associated biomarkers with the presence, incidence and progression of knee OA [31]. 
The median pain VAS score showed a highly significant improvement after 6 months therapy declined to ( $15.75-28.75$ $\mathrm{mm})$ VAS compared to VAS score at the base line was ( $(30-47.5$ $\mathrm{mm}$ ) VAS Correlation between Post-treatment and Pre-treatment on Urinary CTX-II and VAS score showing a statistically significant difference suggesting that patients with decreasing in clinical VAS score tented to have decreasing in laboratory urinary CTX-II but not a statistically significant difference between differences of serum COMP and VAS score before and after treatment of ASU.

The degeneration of articular cartilage, including the degeneration of cartilage cells and matrix, is the main pathological characteristic of $\mathrm{OA}$, However, matrix degeneration mainly results in the losses of proteoglycans and type II collagen. C-telopeptides of type II collagen (CTX-II) is one of the main products of type II collagen degeneration. When type II collagen is degraded, CTX-II is released into the synovial fluid and absorbed by the serum. Cartilage oligomeric matrix protein (COMP) is a tissue specific protein, binds to type II collagen fibers and can stabilize the collagen fiber network of articular cartilage. When the articular cartilage is destroyed, COMP is released into the synovial fluid and absorbed by the serum. Accordingly, the serum levels of CTX-II and COMP reflect the metabolism of type II collagen fibers [32]. These results agree with those of Simental et al (Systematic review and meta-analysis) and Maheu et al who found that ASU therapy had a significant reduction on pain by VAS assessment [33-39].

The best of our knowledge, this was the first study to evaluate the efficacy of ASU on the level of CTX-II and a strength point of this study, no loss of follow-up cases after recruitment at the start. Our study is limited by the relatively small sample size which we considered that is a pilot study due to no previous studies, therefore it may be possible that several significant relationships are yet to be discovered, but are simply not detectable and the lack of reliable control group, Future randomized Controlled trial will be needed to confirm our findings.

\section{Conclusion}

The concentration of urinary CTX-II is significantly higher in the ESKOA patients before using ASU and markedly decreased after 6 months of therapy with ASU. The urinary CTX-II level is highly sensitive to the very early structural changes in the articular collagen, however the serum level of COMP increased significantly only after a long period osteoarthritic changes and with the disease progression. Further randomized double blind placebo-controlled studies for a long follow up period are needed to confirm our findings.

\section{References}

1. Migliore A, Scirè CA, Carmona L, Herrero-Beaumont G, Bizzi E, et al. (2017) Rheumatol Int 37(8): 1227

2. Bay-Jensen AC, Andersen TL, Charni-Ben Tabassi N, Kristensen PW Kjaersgaard-Andersen P, et al. (2008) Biochemical markers of type II collagen breakdown and synthesis are positioned at specific sites in human osteoarthritic knee cartilage. Osteoarthritis Cartilage 16(5): 615-623.

3. Neogi T (2013) The epidemiology and impact of pain in osteoarthritis. Osteoarthritis Cartilage 21(9): 1145-1153.

4. Martin JA, Buckwalter JA (2002) Aging, articular cartilage chondrocyte senescence and osteoarthritis. Biogerontology 3(5): 257-264.

5. Buckwalter JA, Mankin HJ (1998) Articular cartilage: degeneration and osteoarthritis, repair, regeneration, and transplantation. Instr Course Lect 47: 487-504.

6. Felson DT, Anderson JJ, Naimark A, Walker AM, Meenan RF (1988) Obesity and knee osteoarthritis. The Framingham study. Ann Intern Med 109(1): 18-24.

7. Aspden RM, Scheven BA, Hutchison JD (2001) Osteoarthritis as a systemic disorder including stromal cell differentiation and lipid metabolism. Lancet 357(9262): 1118-1120.

8. Ling SM, Patel DD, Garnero P, Zhan M, Vaduganathan M, et al. (2009) Serum protein signatures detect early radiographic osteoarthritis. Osteoarthr Cartil OARS Osteoarthr Res Soc 17(1): 43-48.

9. Baker-LePain JC, Lane NE (2010) Relationship between joint shape and the development of osteoarthritis. Curr Opin Rheumatol 22(5): 538-543.

10. Bliddal H, Leeds AR, Christensen R (2014) Osteoarthritis, obesity and weight loss: evidence, hypotheses and horizons e a scoping review. Obes Rev 15(7): 578e-586.

11. Sellam J, Berenbaum F (2010) The role of synovitis in pathophysiology and clinical symptoms of osteoarthritis. Nat Rev Rheumatol 6(11): 625-635

12. Wang Q, Rozelle AL, Lepus CM, Scanzello CR, Song JJ, et al. (2011) Identification of a central role for complement in osteoarthritis. Nat Med 17(12): 1674-1679.

13. Liu-Bryan R, Terkeltaub R (2015) Emerging regulators of the inflammatory process in osteoarthritis. Nat Rev Rheumatol 11(1): 3544

14. Mobasheri A, Matta C, Zákány R, Musumeci G (2015) Chondrosenescence: definition, hallmarks and potential role in the pathogenesis of osteoarthritis. Maturitas 80(3): 237-244.

15. Greene MA, Loeser RF (2015) Aging-related inflammation in osteoarthritis. Osteoarthritis Cartilage 23(11): 1966-1971.

16. Orlowsky EW, Kraus VB (2015) The role of innate immunity in osteoarthritis: when our first line of defense goes on the offensive. J Rheumatol 42(3): 363-371.

17. Sellam J, Berenbaum F (2013) Is osteoarthritis a metabolic disease? Joint Bone Spine 80(6): 568-573.

18. Courties A, Gualillo O, Berenbaum F, Sellam J (2015) Metabolic stressinduced joint inflammation and osteoarthritis. Osteoarthritis Cartilage 23(11): 1955-1965.

19. Eyre D (2002) Collagen of articular cartilage. Arthritis Res 4(1): 30-35.

20. Louati K, Vidal C, Berenbaum F, Sellam J (2015) Association between diabetes mellitus and osteoarthritis: systematic literature review and meta-analysis. RMD Open 1(1): e000077.

21. Garnero P, Ayral X, Rousseau JC, Christgau S, Sandell LJ, et al. (2002) Uncoupling of type II collagen synthesis and degradation predicts progression of joint damage in patients with knee osteoarthritis. Arthritis \& Rheumatism 46(10): 2613-2624.

22. Garnero P, Landewe R, Boers M, Verhoeven A, Van Der Linden S, et al. (2002) Association of baseline levels of markers of bone and 
cartilage degradation with long-term progression of joint damage in patients with early rheumatoid arthritis: the COBRA study. Arthritis \& Rheumatism 46(11): 2847-2856.

23. Sharma AR, Jagga S, Lee SS, Nam JS (2013) Interplay between cartilage and subchondral bone contributing to pathogenesis of osteoarthritis. Int J Mol Sci 14(10): 19805-19830.

24. Henrotin YE, Sanchez C, Deberg MA, Piccardi N, Guillou GB, et al. (2003) Avocado/soybean unsaponifiables increase aggrecan synthesis and reduce catabolic and proinflammatory mediator production by human osteoarthritic chondrocytes. J Rheumatol 30(8): 1825-1834.

25. Mazières B, Garnero P, Guéguen A, Abbal M, Berdah L, et al. (2006) Molecular markers of cartilage breakdown and synovitis at baseline as predictors of structural progression of hip osteoarthritis. The ECHODIAH Cohort. Ann Rheum Dis 65(3): 354-359.

26. Machold KP, Nell V, Stamm T, Aletaha D, Smolen JS (2006) Early rheumatoid arthritis. Curr Opin Rheumatol 18(3): 282-288.

27. Daghestani HN, Jordan JM, Renner JB, Doherty M, Wilson AG, et al. (2017) Serum Npropeptide of collagen IIA (PIIANP) as a marker of radiographic osteoarthritis burden. PLoS ONE 12 (12): e0190251.

28. Goldring MB, Marcu KB (2009) Cartilage homeostasis in health and rheumatic diseases. Arthritis Res Ther 11(3): 224.

29. Jiao Q, Wei L, Chen C, Li P, Wang X, et al. (2016) Cartilage oligomeric matrix protein and hyaluronic acid are sensitive serum biomarkers for early cartilage lesions in the knee joint. Biomarkers 21(2): 146-151.

30. Kraus VB, Collins JE, Hargrove D, Losina E, Nevitt M, et al. (2017) Predictive validity of biochemical biomarkers in knee osteoarthritis: data from the FNIH OA Biomarkers Consortium. Ann Rheum Dis 76(1): 186-195.

31. Thijssen E, van Caam A, van der Kraan PM (2015) Obesity and osteoarthritis, more than just wear and tear: pivotal roles for inflamed adipose tissue and dyslipidaemia in obesity induced osteoarthritis Rheumatology (Oxford) 54(4): 588-600.

32. Oganesian A, Zhu Y, Sandell LJ (1997) Type IIA procollagen amino propeptide is localized in human embryonic tissues. J Histochem Cytochem 45(11): 1469-1480.

33. Rousseau JC, Sandell LJ, Delmas PD, Garnero P (2004) Development and clinical application in arthritis of a new immunoassay for serum type IIA procollagen NH2 propeptide. Methods Mol Med 101: 25-37.

34. Luyten FP, Denti M, Filardo G, Kon E, Engebretsen L (2012) Definition and classification of early osteoarthritis of the knee. Knee Surg Sports Traumatol Arthrosc 20(3): 401-406.

35. Qazi AA, Folkesson J, Pettersen PC, Karsdal MA, Christiansen C, et al. (2007) Separation of healthy and early osteoarthritis by automatic quantification of cartilage homogeneity. Osteoarthr Cartil OARS Osteoarthr Res Soc 15: 1199-1206.

36. Schiphof D, Oei EHG, Hofman A, Waarsing JH, Weinans H, et al. (2014) Sensitivity and associations with pain and body weight of an MRI definition of knee osteoarthritis compared with radiographic Kellgren and Lawrence criteria: a population-based study in middle-aged females. Osteoarthr Cartil OARS Osteoarthr Res Soc 22(3): 440-446.

37. Baert IAC, Mahmoudian A, Nieuwenhuys A, Jonkers I, Staes F, et al. (2013) Proprioceptive accuracy in women with early and established knee osteoarthritis and its relation to functional ability, postural control, and muscle strength. Clin Rheumatol 32(9): 1365-1374.

38. Aigner T, Zhu Y, Chansky HH, Matsen FA 3rd, Maloney WJ, et al. (1999) Reexpression of type IIA procollagen by adult articular chondrocytes in osteoarthritic cartilage. Arthritis Rheum 42(7): 1443-1450.

39. Kluzek S, Bay-Jensen A-C, Judge A, Karsdal MA, Shorthose M, et al. (2015) Serum cartilage oligomeric matrix protein and development of radiographic and painful knee osteoarthritis. A community-based cohort of middle-aged women. Biomarkers 20(8): 557-564.

\section{Your next submission with Juniper Publishers} will reach you the below assets

- Quality Editorial service

- Swift Peer Review

- Reprints availability

- E-prints Service

- Manuscript Podcast for convenient understanding

- Global attainment for your research

- Manuscript accessibility in different formats ( Pdf, E-pub, Full Text, Audio)

- Unceasing customer service

Track the below URL for one-step submission https://juniperpublishers.com/online-submission.php 